\title{
Neural field model of rat's cortex based on realistic connectivity from diffusion weighted MRI and neural morphology
}

\author{
Manh Nguyen Trong ${ }^{1,2^{*}}$, Andreas Spiegler ${ }^{1,2}$, Thomas R Knösche \\ From Nineteenth Annual Computational Neuroscience Meeting: CNS*2010 \\ San Antonio, TX, USA. 24-30 July 2010
}

Generative models of neural circuits may help to create a link between neural mechanisms and observable data. We propose a model of rat's cortex using a neural field model containing biologically plausible anatomical connections from tractography based on dwMRI data and from the neural morphological database NeuroMorpho [1].

There are three principal types of anatomical connections in the cortex: Local, long-range and distal connections [2].

For specifying local connections we use neural morphologies from [1]. We consider each voxel in the model as a neural mass and distribute randomly drawn neurons from the database therein. After that we use bootstrap methods to determine the total number and variability of synaptic contacts. For the distal connectivity we estimated the degree of anatomical connectedness using white matter tractography on the basis of diffusion weighted MRI [3].

Our neural field consists of 5 layers. For each layer we assume three different neural masses: pyramidal cells, excitatory and inhibitory interneurons [4]. The mutual interactions between neural masses will be described by a system of integral differential equations:

$\left(\frac{\partial}{\partial t}+\frac{1}{\tau}\right)^{2} V(r, t)=H T \int W(r, \tilde{r}) S\left(V\left(r, t-t^{(d)}(r, \tilde{r})\right)\right) d \tilde{r}+(r, t)$ where $\mathbf{V}$ is the state vector (mean membrane potentials), $\mathbf{T}$ the time delays in the dendritic arbors, $\mathbf{S}$ the sigmoidal output

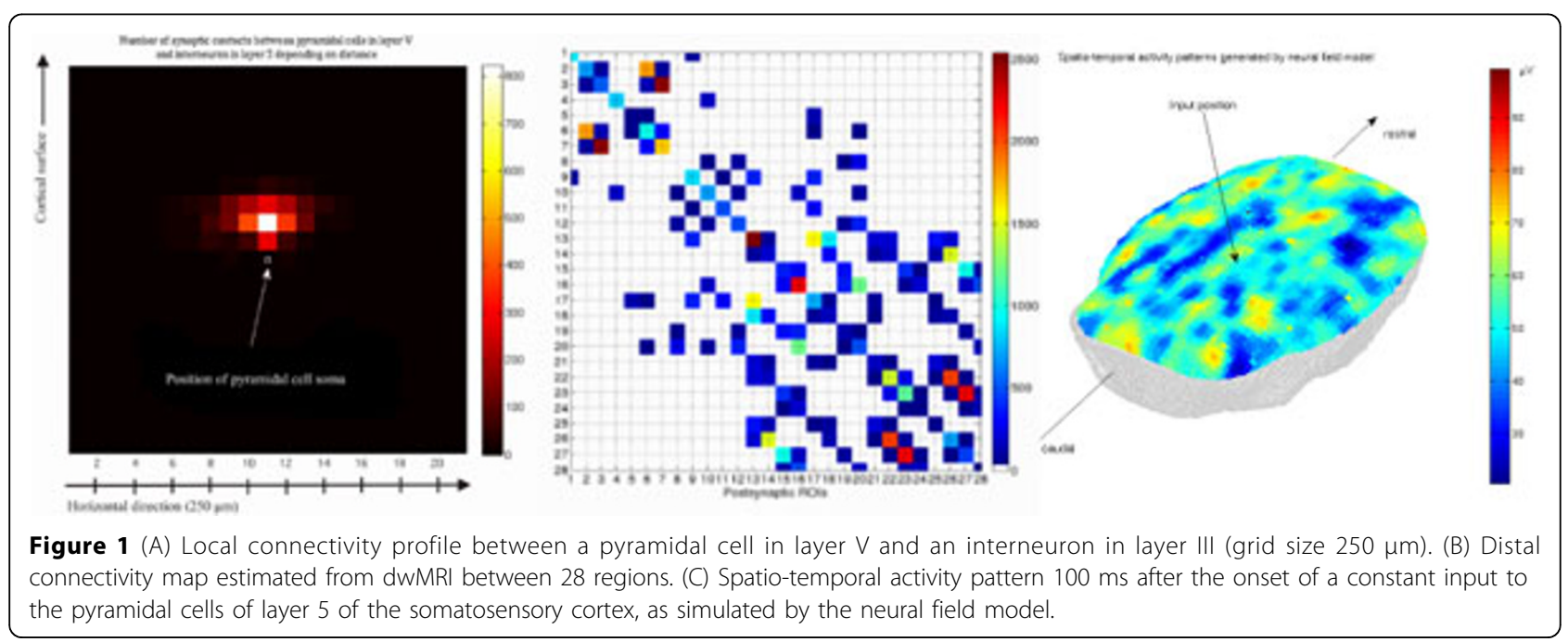

* Correspondence: nguyen@cbs.mpg.de

'Max Planck Institute for Human Cognitive and Brain Sciences, Leipzig, Germany 
function, $\mathbf{W}$ the connection coefficients between the neural elements, I the input, and $t^{(\mathrm{d})}$ is the distance dependent time delays. Figure 1A shows the estimated spatial dependency of local connectivity, which is in accordance with anatomical observations [2]. The distal connectivity map of 28 regions is displayed in Fig. 1B. An example map of simulated activity on the cortex in response to a stimulus to somatosensory cortex is illustrated in Fig. 1C.

To summarize, we developed a method for estimating the local connectivity and constructed a neural field model of the entire cortex enriched by estimated local and distal connectivities. With this model we are able to simulate spatio-temporal activity patterns. This is a first step for a comprehensive dynamic brain model and thereby for understanding complex brain processes.

\footnotetext{
Author details

${ }^{1}$ Max Planck Institute for Human Cognitive and Brain Sciences, Leipzig, Germany. ${ }^{2}$ Institute for Biomedical Engineering and Informatics, Technical

University of IImenau, IImenau, Germany.
}

Published: 20 July 2010

\section{References}

1. Neuromorpho Database: Neural data base. 2009 [http://www. neuromorpho.org].

2. Armut Schüz, Robert Miller: Cortical areas: unity and diversity.Taypor and Francis 2002.

3. Kaden E, Knösche TR, Anwander A: Bayesian analyis of anatomical connectivity using diffusion MRI. Neurolmage 2007, 37(2):474-488.

4. Spiegler A, Kiebel SJ, Atay FM, Knösche TR: Bifurcation analysis of neural mass models: Impact of extrinsic inputs and dendritic time constants. Neurolmage 2010, Corrected Proof DOl: 10.1016/j.neuroimage.2009.12.081.

doi:10.1186/1471-2202-11-S1-P41

Cite this article as: Trong et al:: Neural field model of rat's cortex based on realistic connectivity from diffusion weighted MRI and neural morphology. BMC Neuroscience 2010 11(Suppl 1):P41.

\section{Submit your next manuscript to BioMed Central} and take full advantage of:

- Convenient online submission

- Thorough peer review

- No space constraints or color figure charges

- Immediate publication on acceptance

- Inclusion in PubMed, CAS, Scopus and Google Scholar

- Research which is freely available for redistribution

Submit your manuscript at www.biomedcentral.com/submit
C Biomed Central 